\title{
The Sociology of Medical Screening: Past, Present and Future.
}

\author{
Abstract \\ Medical screening raises fundamental issues for sociological inquiry, but at present a well-developed \\ sociology of medical screening is lacking. This volume on the sociology of screening brings together \\ an exciting collection of new work that tackles medical screening from a variety of theoretical and \\ methodological approaches. In this opening paper, we begin by explaining what we mean by \\ screening, and why we believe screening merits sociological attention. Second, we reflect on the \\ sociology of screening to date and provide an introduction for those new to this area. We then \\ provide an overview of the papers in this collection, highlighting links and contrasts between papers. \\ We conclude by reflecting on sociology's potential contribution to wider debates about screening \\ and propose future research directions.
}

\section{Introduction}

Screening for medical conditions is an important and topical issue. The reach of population-based medical screening is ever-growing and developing; it is now possible to screen for an increasing number of conditions, using ever-more advanced and sophisticated technologies. Medical screening, a key strategy of preventive medicine, raises fundamental issues for sociological inquiry because screening is a social intervention as well as a medical one, and can raise important social dilemmas. However, at present, a well-developed sociology of medical screening is lacking.

As we will go on to explore in more detail below, we believe that sociological work on screening is currently fragmented and has yet to constitute more than the sum of its individual parts. We suggest a number of factors might be contributing to this. First, sociological work on screening tends to be located in a wide range of sub-disciplines without a great deal of cross-fertilisation between and across these. Second, much of this work tends to be confined to studies of screening for particular conditions, and hence may remain largely contained within specialist silos. Third, we would suggest that sociological work on screening currently remains somewhat limited in its analytical scope. This volume has three main aims. First, through both this introduction and David Armstrong's (Armstrong 2012) contribution, we seek to reflect on both the nature of screening itself and the sociological attention it has received to date in order to provide an introduction for those new to this area. Second, we reflect on sociology's potential contribution to wider debates about screening and propose future research directions. Third, we showcase a range of work that constitutes the sociology of screening as it currently stands. The collection of new papers in this volume addresses a 
range of issues from a variety of theoretical and methodological approaches. Taken together, they demonstrate current sociological concerns around screening and make clear suggestions for how research in this area should develop in the future. Our ultimate wish is that this volume serves to stimulate and inspire future research on medical screening that starts to achieve the crossfertilisation of ideas and the production of theoretical approaches that may have purchase across the area of screening as a whole. Before we can embark on those tasks, though, we begin by explaining what we mean by screening, and why we believe screening merits, and indeed requires, sociological attention.

\section{What do we mean by screening?}

The focus of this collection of papers is population-based medical screening; by which we mean that offered to all people within an identified target population, for example based on age and/or sex. This is fundamentally different from both the traditional medical model of diagnosis following a patient's spontaneous presentation of symptoms, and opportunistic case finding in which a doctor tests for a condition during a consultation about another matter. Rather, it involves the purposeful application of tests to an asymptomatic population in order to classify people into those who are unlikely to have or develop a disease and those who are likely to have or develop a disease. In the UK, the National Screening Committee (UKNSC) assesses the evidence for screening programmes and advises the government about implementation (National Screening Committee 2011). The UKNSC defines screening as:

a process of identifying apparently healthy people who may be at increased risk of a disease or condition. They can then be offered information, further tests and appropriate treatment to reduce their risk and/or any complications arising from the disease or condition.

While misdiagnosis is of course possible, this crucial distinction from diagnosis means that all screening programmes involve an inescapable risk of false-positives and false-negatives, in which people are either incorrectly identified as at risk (and therefore subjected to unnecessary further investigation and possibly treatment) or are falsely reassured (and therefore not offered the further investigation and treatment they may require). The distinction from diagnosis is also important from a sociological position; the sociology of screening should not be confused with the sociology of diagnosis (Jutel and Nettleton 2011).

Globally, healthcare organisations differ with regards to the range of screening programmes offered, the groups targeted, the frequency of invitation, and the cost to the 'consumer' (which is obviously dependent on the country's system of healthcare provision). However, costs aside, a similar position 
is taken by many developed countries in terms of currently available and recommended screening programmes. A full account of screening provision across these countries is beyond the scope of this paper. England is a useful example, however. Its current screening programmes include those for: cervical cancer; breast cancer; bowel/colorectal cancer; abdominal aortic aneurism; diabetic retinopathy; and a range of antenatal and newborn screening (including fetal anomalies, infectious diseases in pregnancy, newborn screening, newborn hearing screening, Sickle Cell and Thalassaemia, and the Newborn and Infant Physical Examination Programme). These programmes are systematic population screening programmes, meaning that the whole population eligible to be screened is invited to participate automatically - for example upon reaching a set age - without having to indicate any prior interest. In contrast, further programmes that are in operation, but are not National Screening Committee approved systematic population screening programmes, include: a risk management programme for prostate cancer; Chlamydia screening; and the NHS health checks programme to assess risk of heart disease, type 2 diabetes, stroke and chronic kidney disease (Department of Health 2009). In addition to NHS provision, there has also been a marked increase in screening offered by private companies over recent years. Concerns that individuals could pay private companies for screening that may cause unnecessary anxiety and could lead to further unnecessary investigations have led the UK National Screening Committee to issue guidance on the pros and cons of private provision to both GPs and the public (Cole 2010).

Screening is costly. The cost of the breast cancer screening programme in England, for example, is now estimated at approximately $£ 96$ million per year (NHS Cancer Screening Programmes 2011a) and cervical screening (including the cost of treating cervical abnormalities) has been estimated to cost around $£ 157$ million a year in England (NHS Cancer Screening Programmes 2011b). To maximise cost effectiveness and efficiency, population-based screening programmes target the group(s) of people considered to be most at risk of developing or having a condition in relation to factors such as their age, sex, ethnicity, or physical attributes. Yet the cost effectiveness of a screening programme is by no means the only criterion assessed when considering implementation. Indeed, based on the underlying principle that screening must not do more harm than good, and in order to assure quality in the screening programmes implemented, the UK National Screening Committee requires that criteria about the condition, test, treatment and programme are all met before a programme is implemented (National Screening Committee 2011).1 These criteria still draw to a

\footnotetext{
${ }^{1}$ Full details of the UK National Screening Committee criteria for screening programmes can be found at: http://www.screening.nhs.uk/criteria
} 
large extent on Wilson and Jungner's classic principles (Wilson and Jungner, 1968), as outlined in Box 1.

[BOX 1 ABOUT HERE]

A note on genetic screening

Developments in technology now allow genetic screening for certain conditions and, in some cases, this is delivered through population-based screening. The most widespread example is the incorporation of genetic testing into newborn screening. In the UK this takes place via a heel prick to collect blood from the baby and includes testing for phenylketonuria, congenital hypothyroidism, sickle cell disorders, cystic fibrosis and medium-chain acyl-CoA dehydrogenase deficiency or MCADD, and in the US includes over 50 conditions (Watson et al. 2006).

Predictive genetic testing is, of course, available for many other conditions (for example, Huntington's disease and hereditary breast and ovarian cancer) and has received notable sociological attention. Areas of study include the social and cultural impact of providing people with information relating to their risk for future disease (Davison et al. 1994; Cox and McKellin 1999); the experiences of genetic responsibility that testing and receiving the results may invoke (Hallowell 1999, Raspberry and Skinner 2011, Polzer et al. 2002); and how such genetic responsibility may be gendered (Steinberg 1996, Hallowell et al. 2006, Reed, 2009). However, because genetic testing of this kind is not routinely offered we believe it therefore cannot be considered as population screening; rather individuals are referred for genetic testing by their doctor if there is a family history of a particular genetic condition/disorder or some types of cancer.

\section{Why does screening merit sociological attention?}

Screening programmes are social interventions as much as they are medical interventions, and they can pose challenging ethical, legal and social dilemmas, the sociological scrutiny of which can be particularly useful both in informing the policy, development and implementation of screening programmes, but also in developing sociological theory. Debates and controversies about medical screening are rarely confined to policy makers and health professionals. Contestations about the science underlying population screening are common, and frequently enter the public sphere, engaging with wider societal themes and normative questions. For example, despite evidence that PSA testing does not reduce prostate cancer mortality and can instead cause harm from unnecessary treatment and anxiety, in the US a powerful pro-PSA lobby group contests this and encourages widespread screening. This position has been argued to be associated with the money to be gained by this group from men undergoing testing (Yamey and Wilkes 2002). Another example is the information leaflet on the UK Breast Screening Programme which was recently strongly criticised for 
being misleading, manipulative and not providing the basis for informed consent as the harms (including over-diagnosis and over-treatment) were not clearly explained (Baum et al 2009, Mayor 2010 ) in light of the growing evidence of the uncertainties and extent of over-diagnosis (Gøtzsche and Nielsen 2009, McPherson 2010).

The difficulty of establishing a screening test with maximum sensitivity and specificity (thereby avoiding as many false negative and false positive results as possible) is often underestimated and underrepresented in the popular press. Instead pleas for new or extended screening programmes from lobby groups, which may be constructed as rights or entitlements, can overshadow the science - as demonstrated in the UK in 2009 when calls to reduce the age at which routine cervical screening commences were provoked by the high profile death of the reality television star Jade Goody at the age of 27. In 2003, the NHS Cervical Screening Programme in England had standardised the age at which women are first invited for cervical screening to 25 years (rather than the previous 20 years) and Jade Goody's death led to considerable pressure for a re-lowering of the starting age. This pressure endured even after the government's Advisory Committee on Cervical Screening reviewed this decision in May 2009 and agreed unanimously there should be no change (Advisory Committee on Cervical Screening 2009). In June 2010 the family of Claire Allen, who died of cervical cancer at the age of 23 years, presented a petition to Downing Street again calling for the screening age to be lowered (Department of Health 2010).

Screening has received significant attention from health psychology, with the focus primarily upon non-attendance for screening (for example Neilson and Jones 1998, McCafferey et al. 2001) and the investigation of factors that may predict screening attendance/non-attendance including: sociodemographic factors (see Jepson et al. 2000); variations in invitation type (Norman and Conner, 1992); social cognition models (for example Bish et al. 2000); educational interventions (for example Wardle et al. 1993); and, more recently, variations in information leaflet content (including details about the costs and benefits of screening) to investigate informed choice (Marteau et al. 2010). A second area of concern for psychologists, driven by the criterion that screening must not do more harm than good, is the psychological impact of screening on individuals. This has involved investigations into the anxiety associated with receipt of abnormal test results and the requirement to attend for further tests (for example, Brett et al. 2005, Orbell et al. 2008). Furthermore, the potential impact of receiving negative test results (i.e. 'not at risk') has received attention arising from concern that such results could convey a feeling of 'false reassurance', (Pettigrew et al. 2000) and in turn trigger a 'certificate of health' effect - meaning that the individual interprets the results as a 'green light' to continue an unhealthy lifestyle (Tymstra and Bieleman 1987). 
While there is a crossover between the aspects of screening studied by psychologists and sociologists; for example, studies of the socio-demographic barriers to uptake and the experience and impact of undergoing screening, there are many differences - not least in theoretical and methodological approach, but also in the underlying assumptions and aims. For example, psychologists may use an experimental design to investigate the impact of the manipulation of factors (such as type of information provided) on cognitions, intentions and behaviour related to screening uptake, and thereby provide those overseeing screening programmes with evidence to guide the design of promotional material and invitations to participate in a programme (for example, Dillard et al. 2011, Marteau et al. 2010). In contrast, sociological critiques (such as surveillance and medicalisation) may question a screening programme's materials, and in turn its purpose, as we will describe in the next section.

\section{Sociological work on screening to date}

A corpus of sociological work has begun to address population-based medical screening in recent years and has begun to develop important insights that allow us to take a more critical view and move beyond the issue of attendance or non-attendance. This paper is not an exhaustive literature review of sociological work on screening, but rather, provides a broad brush look at some of the more significant sociological insights on screening developed thus far.

One of the central tenets of public health strategies such as population-based screening is that nonsymptomatic individuals should make their bodies available to health professionals for regular inspection, and that this process needs to be routinised if it is to protect the health of citizens. These assumptions have received much sociological attention and a sizeable body of sociological work has developed over the last two decades or so that focuses on how health status, and the means for achieving and maintaining good health (including participation in screening programmes), has become a predominant concern of modern society (see for example Lupton 1995, Nettleton and Bunton 1995, Petersen and Lupton 1996).

The increased observation and surveillance of the population has been explored at length by David Armstrong $(1983,1993,1995)$ and has been termed 'surveillance medicine'. The premise of this concept is that a new model of medicine can be seen as emerging during the twentieth century that is concerned with the observation and monitoring of apparently healthy populations. This observation of the seemingly healthy population serves to break down the traditional distinction between those that are healthy and those that are ill. Medicine is no longer concerned simply with the latter; instead, the whole population comes under surveillance and is potentially 'at risk' (Armstrong 1995). 
A significant thread of sociological work on screening has drawn on and developed these ideas, often using cervical screening as case material - a particularly amenable example as it involves women being invited at regular intervals through much of their adult life, therefore providing a large and easily accessible pool of potential research participants. Howson $(1998,1999)$ has problematised women's attendance for cervical screening and linked this to wider debates about the exercise of power within society. Drawing attention to how much of the previous literature and research on cervical screening had adopted an unproblematic view of attendance (seeing it as a consequence of rational decision-making and as morally neutral), Howson argued that the act of attendance for screening needed to be more fully explored and can, in fact, be seen as highly problematic. She argues that it:

can also be understood as a response to a particular expression of power or set of normative expectations...compliance with screening cannot be viewed exclusively as a neutral, if desirable, outcome but as a social practice, which is embedded within a moral framework of responsibility and obligation. (Howson 1999:402)

Thus, a key contribution of sociological attention to screening (which is transferable beyond this particular case - see for example Griffiths et al. (2010) on breast cancer screening) has been to draw attention to the ways in which screening attendance can be understood as a response to normative expectations about what constitutes the most sensible and responsible course of action. Attendance at screening may thus be understood as signifying responsible behaviour that demonstrates good citizenship - in Howson's terms, screening attendance becomes a form of 'moral obligation'.

This felt 'moral obligation' to attend for screening has been explored in relation to female embodiment. For example, the obligation that women may feel to respect and look after their bodies (Bush 2000), and the potential to draw on ideas of the surveillance of women's bodies and sexuality in order to understand the cervix as a site of contested control within the female body (McKie 1995). An individual woman's participation within the screening programme may therefore represent more than simply her concern for disease prevention if participation comes to be based more on perceived normalcy and expectation and less on the basis of personal choice. It should be noted, however, that resistance to these powerful discourses is possible (see for example Armstrong 2007).

There is an increasing focus instigated by the UK National Screening Committee (UK National Screening Committee 2000) on screening based on informed consent rather than on an expectation of attendance (Jepson et al. 2007). The manifest function of information material accompanying invitations to participate in screening is to inform individuals' decision-making about participation. 
However, the tensions between informed choice and ensuring optimal uptake of screening have been discussed within both health policy and medical sociology spheres (Raffle 2001). One immediate issue is what constitutes 'full information' and how this imperative fits with providing information that is accessible to the target audience. Adapting technical information for a generalist lay audience necessarily involves simplification and selectivity. The information provided may also be influenced by a desire to present screening in particular ways. For example, Braun and Gavey (1999) argue that cervical cancer prevention policy in New Zealand largely suppressed sexual risk factor information as policy makers sought to avoid linking cervical cancer and screening to sexual promiscuity or adventurousness in order to avoid potential stigma and maintain attendance levels. However, the provision of written information materials (typically in the form of leaflets that accompany invitations) is likely to be only one part of the much bigger and more complex picture of the factors and issues which influence and inform how people make decisions about whether to have screening, as sociological work across a range of screening types is beginning to show. Pertinent issues include those relating to the technologies or techniques used in screening (see for example Chapple et al. (2008) on the faecal occult blood test for bowel cancer screening); how individuals think about and understand their own risk of developing a particular condition (see for example Pfeffer 2004, Armstrong 2005); the possible influence of the wider context in which screening is offered (see for example Pilnick 2008, Todorova et al. 2006); and how those invited to participate in particularly sensitive or new types of screening act as 'moral pioneers' (Williams et al. 2005, Markens et al. 2010).

The wider sociological concern with issues of risk and uncertainty has also proved to be fertile ground for those seeking ways into thinking sociologically about screening. For example, Green et al. (2002) explored the role that health technologies such as breast cancer screening may play in the 'management' of midlife women's bodies, and the way in which messages about these technologies and their potential are interpreted by women, and Griffiths et al. (2006) have used uncertainty as a way of thinking about the issues faced by health professionals in balancing individual and population costs and benefits of screening for breast cancer. In cases where screening has highlighted that there may (potentially) be a problem, the uncertainty experienced by individuals and the ways in which they attempt to understand and cope with this uncertainty has been a particular area of focus; for example, in relation to cervical abnormalities (Blomberg et al. 2009, Forss et al. 2004, Kavanagh and Broom 1998), prenatal screening (Heyman et al. 2006) and newborn screening (Grob 2008).

To summarise, work on the sociology of screening to date has been informed by and contributed to a range of theories including: surveillance medicine, citizenship and responsibilisation; embodiment; 
decision making and informed choice; and risk and uncertainty. We now move on to reflect on why this work has not been brought together previously.

\section{What's holding a sociology of screening back?}

Despite marked sociological interest in health promotion and preventative interventions more widely during the mid to late 1990s (for example Peterson and Lupton 1996, Nettleton 1995, Burrows et al. 1995, Castel 1991, Lupton 1995, Armstrong 1993), sociological work on screening can be characterised as fragmented and widely dispersed making this focused collection of sociological analysis of screening an important step forward in consolidating and stimulating work in this area.

There are a number of possible factors contributing to why a sociology of screening is not further advanced than it currently is. First, at present, the sociological study of screening is largely undertaken within a range of specific sub-disciplines under the broad disciplinary umbrella of sociology. The discipline of sociology of health and illness is the home for much of this work, but work is also going on in other areas of sociology including science and technology studies; human reproduction; sociology of the body and embodiment; and risk and society. In addition, much sociological work on screening draws on particular ideological or theoretical positions (for example, that may be linked to the sub-discipline in which the work is grounded) or methodological traditions (there is, for example, a body of work on informed choice in relation to screening conducted through conversation analysis). The danger is that this may result in work which speaks primarily to audiences concerned with, or interested in, these theoretical or methodological approaches, rather than having a broader appeal to the wider sociological audience. We would suggest communication across these clusters is not as good as it might be, meaning that this body of work is not yet realising its full potential and has so far failed to become more than the sum of its individual parts.

Second, one could argue that the tendency for researchers to focus on specific examples of screening when conducting empirical work leads to their insights largely remaining contained within these case studies. So, for example, while empirical work on different kinds of screening may draw on similar sociological theories and concepts in order to frame and inform the work, the subsequent findings are not always then fed back up to a broader sociological audience where they may contribute to the development and refinement of theoretical and conceptual approaches. Thus, while there are indeed useful pockets of work focusing on a diverse range of screening examples, there is relatively little evidence that these are cross-fertilising or stimulating the production of theoretical approaches that might have purchase across the area of screening as a whole. Many of the theoretical or conceptual ideas that emerge from and within particular examples (such as the management of uncertainty, or feelings of obligation and responsibility) may be applied in other 
screening contexts and may indeed benefit from the development and refinement this application could bring, but as yet there is little evidence that this is occurring. This may not be a problem unique to a sociology of screening though, as medical sociology more generally has been characterised as relatively atheoretical (Bird et al. 2000, Annandale 1998), and this appeared to be reflected in a comparative analysis of journal content (Seale 2008).

Finally, many sociologically important questions have not yet been addressed either empirically or theoretically by the existing literature, and the agenda for future research is underdeveloped. We turn to this issue in the following section.

\section{Where next for a sociology of screening?}

The selection of papers in this volume brings together the work of scholars from different branches of sociology to demonstrate the range of theoretical and methodological approaches currently guiding sociological scrutiny of different aspects of medical screening. We argue, firstly, that this collection showcases the sociology of screening as it currently stands and, secondly, that it demonstrates several important recent trends.

First, there is an increasing focus on going beyond individuals' experiences of screening. Some of this (but not all) corresponds with another increase we have noted - in ethnographic approaches (for example Kehr 2012, Timmermans and Buchbinder 2012). This is in line with the argument that a sociology of screening should not concern itself solely with the experiences of individuals, be they potential or actual patients or health professionals, but that further attention to the infrastructure of screening is required (Singleton 1998). Indeed as the demand for new technologies increases, sociological scrutiny of these developments, their implementation, and their impacts is vital. The 'bigger picture' questions tackled in papers such as those by Faulkner (2012), Hogarth et al. (2012), and Timmermans and Buchbinder (2012), make important contributions by exploring and critically examining how screening technology is developed and implemented; how knowledge is produced; the roles of key players - both at the 'blunt' end (i.e. at the level of policy makers) and the 'sharp' end (for example, in the screening consultation); and the reach of screening programmes. On another level, as globalisation continues to impact on the make-up of a country's population, and health inequalities continue to widen, there will be increasing need to pay attention to the reach of screening programmes and their implications for particular groups within society, for example as discussed by Kehr (2012).

Second, we earlier emphasised the need for studies that do focus on the screening experience to develop and extend theories and concepts that can be more widely applied across the sociology of screening. Gillespie's concept of measured vulnerability (Gillespie 2012) is a good example, as is 
Timmermans and Buchbinder's bridging work (Timmermans and Buchbinder 2012) and Hogarth and colleagues' extension of the concept of molecularisation (Hogarth et al. 2012).

In addition to these new directions in the sociological study of screening, it is important to reflect on the continuation and development of established analytical approaches to screening. For example, a conversation analytic approach to screening consultations and encounters which continues to contribute to our understanding of the key interactional processes involved (Pilnick and Zayts 2012). Furthermore, pivotal concepts- for example risk and society, surveillance and embodiment continue to be drawn upon as demonstrated by the papers in this collection. We would argue that as the reach of population-based medical screening grows, so will the range of available foci for a sociology of screening, and, in turn, the amount that sociology can contribute.

We turn now to the collection of papers in this volume; providing a brief overview of each and highlighting key links between them.

\section{Introduction to the collection}

David Armstrong's Screening: mapping medicine's temporal spaces presents a genealogy of population screening (Armstrong 2012). The paper charts the history of the use of the term 'screening' from initial metaphors early in the 20th century, through the first organised programmes identifying disease in the inter war years, to contemporary debates about the implications and potential harms of screening. Concurrently it maps the associated changing conceptualisation of illness in terms of its temporality and, related to this, the changing nature of the patient from a passive recipient of medical procedures to a subjective and autonomous one.

Armstrong's sources include medical journals, editorials and correspondence thus the resulting story follows a trajectory of a phenomenon's beginnings, growth and successful widespread implementation, followed by emergence of unforeseen implications and dilemmas. It is interesting to contrast this story with the parallel rising demand for screening programmes, evident in the agendas and voices of policy makers, lobbyists and the public.

Armstrong describes the emergence of the 'risk factor' as the focus of screening and the resulting changes in how illness is conceived, in particular in terms of its temporal trajectory. The 'risk factor' and the argument that risk constitutes an illness in and of itself are the focus of the third paper, The experience of risk as 'measured vulnerability': health screening and lay uses of numerical risk. Focusing on the cases of high cholesterol and of raised PSA levels, Chris Gillespie uses empirical data to examine how people interpret and experience risk in their everyday lives following receipt of a 'high risk' result (Gillespie 2012). He explores the lay (and sometimes professional) tendency to 
interpret numerical measures of health, and the importance of numbers not only in the diagnosis of risk but in the management of uncertainty (and vulnerability) arising from that risk. His resulting concept - measured vulnerability - acknowledges the significance that numbers hold in the diagnosis and management of the lived risk experience, as well as the vulnerability to which this use of numerics leads.

A key strength of Gillespie's paper relates to our argument about the need to develop theoretical and conceptual ideas from studying one type of screening that can be applied to a variety of screening contexts. Gillespie goes beyond studying lay experiences of screening from an 'experiences of health and illness' framework, to develop a concept that is applicable to medical screening in general, which thus becomes a key concept in the sociology of medical screening to be refined by future work. This strength is also demonstrated by the next paper from Stefan Timmermans and Mara Buchbinder, Expanded newborn screening: articulating the ontology of diseases with bridging work in the clinic (Timmermans and Buchbinder 2012). While Gillespie's paper focuses on the uncertainty experienced by lay people following receipt of numerical screening test results, Timmermans and Buchbinder explore another type of uncertainty that can arise from the implementation of a screening programme - uncertainty in knowledge about the condition being screened for, as experienced by clinicians and parents of children identified with a metabolic disease following newborn screening.

Timmermans and Buchbinder unpack one of Wilson \& Jungner's criteria (Wilson and Jungner 1968) for screening - that the natural history of the condition, including development from latent to declared disease, should be adequately understood - by demonstrating how a screening programme itself can transform knowledge about a disease. In their ethnographic study of a clinical centre for metabolic-genetic disorders, they demonstrate how the implementation of population-based newborn screening for medium chain acyl-CoA dehydrogenase deficiency (MCADD) led to changes in knowledge about the condition, its variants and anomalies. They introduce the concept of 'bridging work' to describe how clinicians reconcile this gap in knowledge; this comprised the team collectively engaging in continuous learning about the disease and developing procedures to manage the changed ontology, while practically - in the clinic - adapting patient care in light of the changed knowledge.

Next we take a step back and consider aspects related to what can be conceptualised as the 'blunt' end of screening - the development, initiation, implementation and evaluation of screening programmes. The goal of finding testing technology with optimal sensitivity and specificity is a key aspect of this; and a focus on the companies that develop these, and the scientific assessment and 
governance of these, unsurprisingly attracts sociological attention. Conditions for which no systematic population screening programme is currently in place, but that have received considerable scrutiny from policymakers provide a particularly useful case studies. A pertinent example, which has been the subject of controversy in the UK, is the screening and detection of localised prostate cancer, and this is the focus of Alex Faulkner's paper Resisting the screening imperative: patienthood, populations and politics in UK prostate cancer detection technologies (Faulkner 2012). Faulkner outlines the controversy and uncertainty surrounding the issue and describes recent technological developments including PSA testing, the search for genetic biomarkers and genome-wide association tests. He analyses the response to these developments by drawing on theories of risk and governance, the sociology of technology governance and the sociology of technology expectations. In doing so he charts the different modes of resistance demonstrated by public health policymakers and reflects on the shift in policy to an 'informed choice' framework.

The search for genetic and genomic detection technology, and its relationship with established testing technology, is not limited to prostate cancer. Stuart Hogarth and colleagues track the development of gene-based diagnostic testing for cervical cancer detection in their paper, Muffled molecularisation: the place of HPV testing in cervical screening programmes (Hogarth et al. 2012). While Faulkner reflects on key players in terms of the policy, regulation and governance of testing technologies, Hogarth and colleagues narrow their focus onto a diagnostics company, Digene, and critically examine the company's development and marketing of a molecular alternative to the Pap smear. Using a science and technology studies framework, Hogarth and colleagues extend the concept of molecularisation to examine and illustrate how the process of genomic molecularisation plays out in this context of screening. They use their findings to demonstrate a cumulative process with the new technology integrating with the established method. Second, when examining corporatisation, they demonstrate the growing importance of diagnostics companies in developing and disseminating innovation in this area.

The next paper continues a focus on key players in the implementation of screening programmes. As described by Armstrong, the drive to diagnose, prevent and eradicate tuberculosis (TB) triggered the first instances of screening. While population-wide screening for TB is no longer required in developed countries, targeted TB screening in migrant populations is the focus of Janina Kehr's paper, Inclusion/Exclusion. Tuberculosis screening between social risk and political responsibility in contemporary France and Germany (Kehr 2012). In her multi-site ethnographic study of TB prevention centres, Kehr critically examines each country's guidelines to explore how they are 
enacted on the ground in each case. In doing so, she highlights problems and implications throughout the process - from the collection of epidemiological data (particularly in terms of what is not collected), through to the treatment of cases identified through screening (and the difficulty of ensuring treatment completion). In distinguishing her findings from previous studies of TB screening and of public health practice, she argues that, rather than being stigmatising and surveying, these two examples of targeted migrant TB screening are exclusionary through being ineffective and constrained by political measures. She argues that TB screening is political in nature, and concerned with controlling disease not treating the people who have it.

The next few papers explore different aspects of what we conceptualise as the 'sharp end' of screening - sociological studies of the screening consultation. The first two papers focus on prenatal screening consultations. First, Alison Pilnick and Olga Zayts examine the interactional processes involved in decision making following a 'high risk' screening test result for fetal abnormality in their paper, "Let's have it tested first": Directiveness, culture and decision-making following positive antenatal screening in Hong Kong (Pilnick and Zayts 2012). Reflecting on debates about the principle of non-directiveness in antenatal screening, they point out that the interactional nature of antenatal screening means that directiveness is likely to be an unintended outcome. Indeed, through conversation analysis (CA) of videoed consultations, they argue that the visibility of a woman's socioeconomic background or circumstances can impact on how a consultation is played out, including how decisions are made, and how they are accepted or challenged by the counselling professionals.

In the paper Representing and intervening: Doing good care in first trimester prenatal risk assessment (FTPRA), Nete Schwennesen and Lene Koch demonstrate not only that non-directiveness is not achieved in prenatal counselling, but also argue that complete non-directiveness in these consultations would not constitute good care (Schwennesen and Koch 2012). In their ethnographic study in Danish ultrasound clinics, they explore processes of knowledge production and decision making at two key passage points of first trimester prenatal risk assessment (FTPRA) - the performance of the ultrasound scan, and the communication of the risk figure and subsequent discussion about the woman's decision. They argue that sonographers employ three different modes of 'doing good care' instead of non-directiveness to achieve the same aim of providing an ethical and accountable approach to prenatal counselling: attuning knowledge and expectations throughout; allowing space for resistance; and providing situated influence in the context of uncertainty.

As we have seen, uncertainty is an implicit theme running through all of the empirical papers in this collection. Schwennesen and Koch (2012) demonstrate how women use the FTPRA consultation to 
deal with this uncertainty - by gaining knowledge about the likely risk to their fetus and the meaning of the risk figure - but often also to ask for guidance in making a decision following receipt of such complex risk knowledge. In the final paper in this collection Julie Roberts demonstrates a different use of screening; in her paper on privately-provided four-dimensional bonding scans during pregnancy, she explores a new social practice of using screening technologies for non-medical purposes (Roberts 2012).

Ultrasound is routinely used within antenatal care and, in the UK, the NHS Fetal Anomaly Screening Programme includes an ultrasound scan at about 18-20 weeks which may detect structural abnormalities such as spina bifida. However, as Roberts outlines, the boundaries between the medical and social components of this are blurred as parents-to-be are frequently at least as, if not more, interested in 'seeing' and 'getting to know' the baby as they are with the clinical significance of the scan. Drawing on ethnographic research in the UK, 'Wakey wakey baby': narrating fourdimensional (4D) bonding scans explores the issues and tensions raised when this screening technology moves outside the clinical setting and begins to be used for social rather than medical purposes.

\section{Conclusion}

As we have said, our aims for this volume are threefold: to reflect on the sociology of screening to date; to suggest ways in which the sociology of screening could move forward; and to bring together a collection of new papers demonstrating current sociological work on screening. We have addressed the first two aims in this introductory paper. The rest of this volume addresses our third aim and showcases a range of work that constitutes the sociology of screening as it currently stands. The varied contributions address a range of issues using several different theoretical and methodological approaches. Taken together, they both demonstrate current sociological concerns around screening and make clear recommendations for future sociological work in this area.

Contemporary debates about population-based medical screening are currently taking place across a variety of forums and involve diverse stakeholders, from patients' groups to policy-makers and health service managers, and from laboratory scientists to clinicians (as demonstrated by Faulkner, 2012). Many of these debates are very heated, with frequent claims and counter-claims made to support particular positions and interests. It almost goes without saying that the kinds of evidence that particular groups draw upon and cite in support of their positions and demands can vary enormously, with a common juxtaposition being discernible between personal experience or understanding of a disease on the one hand and epidemiological study and technical principles on the other (see for example, Barker and Galardi 2011, Armstrong and Murphy 2008, Armstrong et al. 
2010, Wieser 2010, Lehoux et al. 2010). Developing a rigorous and focused sociology of screening will help to invigorate and inform these debates, in particular by affording deeper recognition of the social and ethical implications of screening, and contribute to the evidence-base on which policy and practice is founded.

\section{Acknowledgments}

We are grateful to Elizabeth Murphy, Mary Dixon-Woods, Julia Lawton and Hannah Bradby for helpful comments and suggestions on an earlier draft of this paper. We would also like to thank the authors of the nine papers we have brought together for this volume. 


\section{References}

Advisory Committee on Cervical Screening. (2009) Minutes of extraordinary meeting to re-examine current policy on cervical screening for women aged 20-24 years taking account of any new evidence and to make recommendations to the National Cancer Director and Ministers. Available at: http://www.cancerscreening.nhs.uk/cervical/cervical-review-minutes-20090519.pdf

Annandale, E. (1998) The Sociology of Health and Medicine: a Critical Introduction. Cambridge: Polity Press.

Armstrong, D. (1983) Political Anatomy of the Body. Cambridge: Cambridge University Press.

Armstrong, D. (1993) Public health spaces and the fabrication of identity, Sociology, 27(3), 393-410.

Armstrong, D. (1995) The rise of surveillance medicine, Sociology of Health \& Illness, 17, 393-404.

Armstrong, D. (2012) Screening: mapping medicine's temporal spaces, Sociology of Health \& Illness, Vol TBC

Armstrong, N. (2005) Resistance through risk: women and cervical cancer screening, Health, Risk and Society, 7, 161-176.

Armstrong, N. (2007) Discourse and the individual in cervical cancer screening, Health: An Interdisciplinary Journal for the Social Study of Health, Illness and Medicine, 11, 69-85.

Armstrong, N. and Murphy, E. (2008) Weaving meaning? An exploration of the interplay between lay and professional understandings of cervical cancer risk, Social Science \& Medicine, 67, 1074-82.

Armstrong, N. Dixon-Woods, M. and Murphy, E. (2010) Age criteria for cervical screening in England: qualitative study of women's views, Department of Health Sciences, University of Leicester Working Papers Series No.10:01 Available at: http://hdl.handle.net/2381/8782

Barker, K.K. and Galardi, T.R. (2011) Dead by 50: Lay expertise and breast cancer screening, Social Science \& Medicine, 72, 1351-58. 
Baum, M., McCartney, M., Thornton, H. and Bewley, S. (2009) Breast cancer screening peril: Negative consequences of the breast screening programme, The Times, Feb 19.

Bird, C.E., Conrad, P. and Fremont, A.M. (2000) Medical sociology at the millennium. In Bird, C.E., Conrad, P. and Fremont, A.M. (eds) Handbook of Medical Sociology: 5th Edition. New Jersey: Prentice Hall.

Bish, A., Sutton, S. and Golombok, S. (2000) Predicting uptake of a routine cervical smear test: a comparison of the health belief model and the theory of planned behaviour, Psychology \& Health, $15,35-50$.

Braun, V. and Gavey, N. (1999) 'With the best of reasons': cervical cancer prevention policy and the suppression of risk factor information, Social Science \& Medicine, 48, 1463-74.

Brett, J., Bankhead, C., Henderson, B., Watson, E. and Austoker, J. (2005) The psychological impact of mammographic screening: a systematic review, Psycho-oncology, 14, 917-938.

Bush, J. (2000) "It's just part of being a woman": cervical screening, the body and femininity, Social Science \& Medicine, 50(3), 429-444.

Burrows, R., Nettleton, S. and Bunton, R. (1995) Sociology and health promotion: health, risk and consumption under late modernism. In Bunton, R., Nettleton, S. and Burrows, R. (eds) The Sociology of Health Promotion: Critical Analyses of Consumption, Lifestyle and Risk. London: Routledge. pp. 110.

Castel, R. (1991) From dangerousness to risk. In Burchell, G., Gordon, C. and Miller, P. (eds.) The Foucault Effect. London: Harvester Wheatsheaf. pp. 281-298.

Chapple, A., Ziebland, S., Hewitson P. and McPherson, A. (2008) What affects the uptake of screening for bowel cancer using a faecal occult blood test (FOBt): A qualitative study, Social Science \& Medicine, 66, 2425-35.

Cole, A. (2010) UK patients are given advice on private screening, BMJ, 341:c5394 
Cox, S.M. and McKellin, W. (1999) 'There's this thing in our family': predictive testing and the construction of risk for Huntington Disease, Sociology of Health \& Illness, 21, 622-46.

Davison, C., Macintyre, S., and Davey Smith, G. (1994) The potential social impact of predictive genetic testing for susceptibility to common chronic diseases: a review and proposed research agenda, Sociology of Health \& IIIness, 16, 340-71.

Department of Health. (2009) Free NHS health check: Helping you prevent heart disease, stroke, diabetes and kidney disease. London: Department of Health.

Department of Health. (2010) Comment on calls to lower cervical cancer screening age. Available at: http://www.dh.gov.uk/en/MediaCentre/Statements/DH_116591 (accessed 31.8.2011)

Dillard, A.J., Ferrer, R.A., Ubel, P.A. and Fagerlin, A. (2011) Risk perception measures' associations with behavior intentions, affect, and cognition following colon cancer screening messages. Health Psychology, (online only- to be completed).

Faulkner, A. (2012) Resisting the screening imperative: patienthood, populations and politics in prostate cancer detection technologies in the UK, Sociology of Health and Illness, Vol TBC

Gillespie, C. (2012) The experience of risk as 'measured vulnerability': health screening and lay uses of numerical risk, Sociology of Health and Illness, Vol TBC

Gøtzsche, P.C. and Nielsen, M. (2009) Screening for breast cancer with mammography. Cochrane Database of Systematic Reviews, 1, CD001877.

Green, E., Thompson, E. and Griffiths, F. (2002) Narratives of risk: women at midlife, medical 'experts' and health technologies, Health, Risk \& Society, 4, 273-86.

Griffiths, F., Green, E. and Bendelow, G. (2006) Health professionals, their medical interventions and uncertainty: A study focusing on women at midlife, Social Science \& Medicine, 62, 1078-90. 
Griffiths, F., Bendelow, G., Green, E. and Palmer, J. (2010) Screening for breast cancer: Medicalization, visualization and the embodied experience, Health, 14, 653-68.

Grob, R. (2008) Is my sick child healthy? Is my healthy child sick?: changes parental experiences of cystic fibrosis in the age of expanded newborn screening, Social Science \& Medicine, 67, 1056-1064.

Hallowell, N. (1999) Doing the right thing: genetic risk and responsibility, Sociology of Health and Illness Vol.21 No.5 pp.597-621

Hallowell, N., Arden-Jones, A., Eeles, R., Foster, C., Lucassen, A., Moynihan, C. and Watson, M. (2006) Guilt, blame and responsibility: men's understanding of their role in the transmission of BRCA1/2 mutations within their family, Sociology of Health \& IIIness, $28,969-88$.

Heyman, B., Lewando Hundt, G., Sandall, J., Spencer, K., Williams, C., Grellier, R. and Pitson, L. (2006) On being at higher risk: prenatal screening for chromosomal anomalies, Social Science \& Medicine, $62,2360-2372$.

Hogarth, S., Hopkins, M. and Rodriguez, V. (2012) A molecular monopoly? HPV testing, the Pap smear and the molecularisation of cervical cancer screening in the USA, Sociology of Health and Illness, Vol TBC.

Howson, A. (1998) Embodied obligation: the female body and health surveillance. In Nettleton, S and Watson, J. (eds.) The Body in Everyday Life. London: Routledge. pp. 218-240

Howson, A. (1999) Cervical screening, compliance and moral obligation, Sociology of Health \& Illness, 21(4), 401-425.

Howson, A. (2001) Locating uncertainties in cervical screening, Health, Risk \& Society, 3, 167-79.

Jepson, R., Clegg, A., Forbes, C., Lewis, R., Sowden, A. and Kleijnen, J. (2000) The determinants of screening uptake and interventions for increasing uptake: a systematic review, Health Technology Assessment, 4 (14). 
Jepson, R.G., Hewison, J., Thompson, A. and Weller, D. (2007) Patient perspectives on information and choice in cancer screening: A qualitative study in the UK, Social Science \& Medicine, 65, 890-99.

Jutel, A. and Nettleton, S. (2011) Towards a sociology of diagnosis: reflections and opportunities. Social Science \& Medicine, 73(6), 793-800.

Kavanagh, A.M. and Broom , D.H. (1998) Embodied risk: my body, myself? Social Science \& Medicine, $46,437-444$.

Kehr, J. (2012) Blind spots and adverse conditions of care. Tuberculosis screening of migrants in France and Germany, Sociology of Health \& Illness, (Vol TBC)

Lehoux, P., Denis, J-L., Rock, M., Hivon, M. and Tailliez, M. (2010) How medical specialists appraise three controversial health innovations: scientific, clinical and social arguments, Sociology of Health \& IIIness, 32,123-39.

Lupton, D. (1995) The Imperative of Health. London: Sage

Markens, S., Browner, C.H. and Preloran, H.M. (2010) Interrogating the dynamics between power, knowledge and pregnant bodies in amniocentesis decision making, Sociology of Health \& IIIness, 32, $37-56$.

Marteau, T.M., Mann, E., Prevost, A.T., Vasconcelos, J.C., Kellar, I., Sanderson, S., Parker, M., Griffin, S., Sutton, S. and Kinmonth, A-L. (2010) Impact of an informed choice invitation on uptake of screening for diabetes in primary care (DICISION): randomised trial, BMJ, 340, 1176.

Mayor, S. (2010) Critics attack new NHS breast screening leaflet for failing to address harms, BMJ, 341:c7267

McCaffery, K., Borril, J., Williamson, S., Taylor, T., Sutton, S., Atkin, W. and Wardle J. (2001) Declining the offer of flexible sigmoidoscopy screening for bowel cancer: a qualitative investigation of the decision-making process, Social Science \& Medicine, 53, 679-91. 
McKie, L. (1995) The art of surveillance or reasonable prevention? The case of cervical screening, Sociology of Health \& Illness, 17(4), 441-457.

McPherson, K. (2010) Should we screen for breast cancer? BMJ, 340:c310.

National Screening Committee. (2011) UK screening portal. Available from:

http://www.screening.nhs.uk

Neilson, A. and Jones, R. (1998) Women's lay knowledge of cervical cancer/cervical screening: accounting for non-attendance at cervical screening clinics, Journal of Advancing Nursing, 28, 571575.

Nettleton, S. (1995) The Sociology of Health and Illness. Cambridge: Polity Press

Nettleton, S. and Bunton, R. (1995) Sociological critiques of health promotion. In Bunton, R., Burrows, R. and Nettleton, S. (eds) The sociology of health promotion. London: Routledge.

NHS Cancer Screening Programmes. (2011a)

http://www.cancerscreening.nhs.uk/breastscreen/cost.html (accessed 31.8.2011)

NHS Cancer Screening Programmes. (2011b) http://www.cancerscreening.nhs.uk/cervical/aboutcervical-screening.html\#cost (accessed 31.8.2011)

Norman, P. and Conner, M. (1992) Health checks in General Practice, Family Practice, 9, 481-487.

Orbell, S., O'Sullivan, I., Parker, R., Steele, B., Campbell, C. and Weller, D. (2008) Illness representations and coping following an abnormal colorectal cancer screening result, Social Science \& Medicine, $67,1465-74$.

Petersen, A. and Lupton, D. (1996) The New Public Health. London: Sage

Pettrigrew, M., Sowden, A., Lister-Sharp, D. and Wright, K. (2000) False-negative results in screening programmes: systematic review of impact and implications, Health Technology Assessment, 4(5), 133. 
Pfeffer, N. (2004) Screening for breast cancer: candidacy and compliance, Social Science \& Medicine, $58,151-60$.

Pilnick, A. (2008) "It's something for you both to think about": choice and decision making in nuchal translucency screening for Downs Syndrome, Sociology of Health and Illness, 30(4), 511-30.

Pilnick, A. and Zayts, O. (2012) "Let's have it tested first": Directiveness, circumstance and decisionmaking following positive antenatal screening in Hong Kong, Sociology of Health and Illness, (Vol TBC)

Polzer, J., Mercer, S. L., and Goel, V. (2002) Blood is thicker than water: genetic testing as citizenship through familial obligation and the management of risk, Critical Public Health, 12(2), 153-168

Raffle, A.E. (2001) Information about screening - is it to achieve high uptake or to ensure informed choice?, Health Expectations, 4, 92-8.

Raspberry, K. and Skinner, D. (2011) Enacting genetic responsibility: experiences of mothers who carry the fragile X gene, Sociology of Health \& IIIness, 33, 420-33.

Reed, K. (2009) 'It's them faulty genes again': women, men and the gendered nature of genetic responsibility in prenatal blood screening, Sociology of Health \& Illness, 31, 343-59.

Roberts, J. (2012). 'Wakey wakey baby': narrating four-dimensional (4D) bonding scans, Sociology of Health and Illness, (Vol TBC)

Schwennesen, N. and Koch, L. (2012) Representing and intervening: Doing good care in first trimester prenatal risk assessment (FTPRA), Sociology of Health and Illness, (Vol TBC)

Seale, C. (2008) Mapping the field of medical sociology: a comparative analysis of journals, Sociology of Health \& Illness, 30, 677-695. 
Singleton, V. (1998) Stabilizing instabilities: the role of the laboratory in the United Kingdom cervical screening programme. In Berg, M. and Mol, A. (eds) Differences in medicine: unravelling practices, techniques and bodies. Durham: Duke University Press. pp. 86-104.

Steinberg, D.L. (1996) Languages of risk: genetic encryptions of the female body, Women: a Cultural Review Vol.7 pp.259-270

Timmermans, S. and Buchbinder, M. (2012) Expanded newborn screening: articulating the ontology of diseases with bridging work in the clinic, Sociology of Health \& Illness, (Vol TBC)

Todorova, I.L.G., Baban, A., Balabanova, D., Panayotova, Y. and Bradley, J. (2006) Providers' constructions of the role of women in cervical cancer screening in Bulgaria and Romania, Social Science \& Medicine, 63, 776-87.

Tymstra, T. and Bieleman, B. (1987) The psychosocial impact of mass screening for cardiovascular risk factors, Family Practice, 4(4), 287-290.

UK National Screening Committee. (2000) Second Report of the UK National Screening Committee. Available from:

http://www.dh.gov.uk/prod_consum_dh/groups/dh_digitalassets/@dh/@en/documents/digitalasse t/dh_4014560.pdf

Wardle, J., Williamson, S., McCaffery, K., Sutton, S., Taylor, T., Edwards, R. and Atkin, W. (2003) Increasing attendance at colorectal cancer screening: testing the efficacy of a mailed, psychoeducational intervention in a community sample of older adults, Health Psychology, 22, 99105.

Watson, M.S., Lloyd-Puryear, M.A., Mann, M.Y., Ronaldo, P. and Howell, R.R. (2006) Newborn Screening: Toward a Uniform Screening Panel and System, Genetics in Medicine, 8, 5(Suppl.), 12S.

Wieser, B. (2010) Public accountability of newborn screening: Collective knowing and deciding, Social Science \& Medicine, 70, 926-33. 
Williams, C., Sandall, J., Lewando-Hundt, G., Heyman, B., Spencer, K. and Grellier, R. (2005) Women as moral pioneers? Experiences of first trimester antenatal screening, Social Science \& Medicine, 61, 1983-92.

Wilson, J.M.G. and Jungner, G. (1968) Principles and practice of screening for disease. Public health paper No. 34. Geneva: World Health Organisation. Available at:

http://www.who.int/bulletin/volumes/86/4/07-050112BP.pdf

Yamey, G. and Wilkes, M. (2002) The PSA storm: Questioning cancer screening can be a risky business in America, British Medical Journal, 324:431. 
Box 1. Wilson and Jungner's principles of screening (taken from Wilson \& Junger, 1968)

(1) The condition sought should be an important health problem.

(2) There should be an accepted treatment for patients with recognized disease.

(3) Facilities for diagnosis and treatment should be available.

(4) There should be a recognizable latent or early symptomatic stage.

(5) There should be a suitable test or examination.

(6) The test should be acceptable to the population.

(7) The natural history of the condition, including development from latent to declared disease, should be adequately understood.

(8) There should be an agreed policy on whom to treat as patients.

(9) The cost of case-finding (including diagnosis and treatment of patients diagnosed) should be economically balanced in relation to possible expenditure on medical care as a whole.

(10) Case-finding should be a continuing process and not a "once and for all" project. 